The Effect of Caring on Post-bereavement Outcome: Research Gaps and Practice Priorities

\author{
Lauren J. Breen
}

School of Psychology and Speech Pathology, Curtin Health Innovation Research Institute, Curtin University

Contact details for correspondence:

Dr Lauren J. Breen

School of Psychology and Speech Pathology

Curtin University

GPO Box U1987

Perth Western Australia 6845

Australia

Tel: $\quad+61892667943$

Fax: $\quad+61892662464$

Email: lauren.breen@curtin.edu.au 


\begin{abstract}
Family caregivers are the primary caregivers of family members over the course of illness. Some caregivers exhibit elevated levels of distress following the death of the person for whom they were caring. Despite the practical relevance for providing supports and services to caregivers and families, pre- and post-bereavement, the effect of caregiving on bereavement is obscured. In examining the research literature on caregiving and bereavement, three methodological limitations were identified - caregivers' perspectives on preparing for the death of the person for whom they are caring is typically not assessed; the effect of caring on post-death adjustment tends to be assessed qualitatively, cross-sectionally, and retrospectively; and there is a lack of adequate comparison groups. This paper highlights the need to address two important gaps in understanding the effects of caregiving and bereavement: (1) caregivers' understandings and experiences of the anticipating and preparing for the death of the person for whom they are caring, and (2) the relationship between caregivers' pre-death grief and distress and post-death adjustment. Caregivers relieve significant costs from the health system, and improved support, pre- and postbereavement, will continue to benefit them as well as society. Without significant research investment, palliative care services will continue to operate without a suitable evidence base to support their bereavement care efforts.
\end{abstract}

\title{
Keywords
}

Family Caregivers, Bereavement, Palliative Care, Research Priorities, Evidence-based Practice 


\section{The Effect of Caring on Post-bereavement Outcome: Research Gaps and Practice}

\section{Priorities}

According to the World Health Organization, ${ }^{1}$ chronic diseases, including cardiovascular diseases, cancers, diabetes and chronic lung diseases account for $63 \%$ of deaths worldwide; this proportion is greater in high income nations. ${ }^{2}$ In economicallydeveloped countries, a typical death involves a lengthy period of time whereby the care of patients with chronic and disabling conditions occurs in the home and by one or more family member, usually a spouse or adult child and typically women. ${ }^{3-5}$ Recent years have seen the provision of formal home-based end-of-life services, resulting in family caregivers providing the interface between the person living with chronic disease and the professionals. ${ }^{6}$ Family caregivers continue to provide care when (or if) the patient is admitted to a palliative care unit or hospice near the end-of-life. ${ }^{7}$ Thus, family caregivers are the primary caregivers over the course of the illness.

The experiences and needs of family caregivers during this time are relatively welldocumented. Notwithstanding potential benefits attained from caregiving such as the strengthening their relationship with the patient, the development of new skills, and spiritual growth ${ }^{8}$, and an increased appreciation for life, ${ }^{9}$ family caregivers engage in care that may be financially costly, time consuming, physically demanding, and stigma inducing, and that usually impacts negatively on their ability to engage in social and recreational activities. ${ }^{10-13}$ Needs include practical information, ${ }^{14}$ emotional support, ${ }^{15}$ economic assistance and housing support, ${ }^{13}$ improved coordination of formal care and allied services, ${ }^{16}$ and bereavement support, ${ }^{17}$ while outcomes when engaging in care may include symptoms of psychiatric morbidity ${ }^{18}$ and psychological distress $;{ }^{19}$ these needs remain largely unmet by services. ${ }^{20}$

Despite the practical relevance for providing supports and services to family caregivers, pre- and post-bereavement, the effect of caregiving on bereavement is less clear. 
This paper summarises what is known about the effects of family caregiving on bereavement outcome, and demonstrates that this knowledge is hampered by three serious methodological limitations. The implications for future research in addressing these limitations and developing an evidence-base for bereavement support in palliative care are outlined.

\section{Limitations to Current Understandings of Caring and Bereavement}

A recent review of the caregiving and bereavement literature ${ }^{21}$ demonstrated that the three theories explaining the effect of family caregiving on bereavement are conflicting. The cumulative stress theory proposes that the 'wear and tear' of caring precipitates significant distress following bereavement. On the other hand, the stress reduction theory suggests that family caregivers experience a reduction in their stressors following bereavement, yielding a more favorable post-bereavement adjustment. The third theory concerns the notion of anticipatory grief ${ }^{22,23}$ and suggests that family caregivers engage in much 'grief work' before bereavement. The notion of anticipatory grief is accepted by many end-of-life practitioners, despite its theoretical and empirical challenges. ${ }^{24,25}$

Currently, empirical evidence is equivocal. A pioneering review of the literature on bereavement and caregiving indicated that family caregivers adjusted relatively well to the death of the person for whom they were caring. ${ }^{26}$ However, the ability to draw sound conclusions from the research was encumbered by the studies' use of cross-sectional and retrospective research designs. A more recent review of the caregiving and bereavement literature concluded that, on the whole, family caregiving was not associated with increased distress following bereavement, and in many cases, bereaved caregivers show improvements in their adjustment over time. ${ }^{21}$ While not all bereaved people experience a significant and long-term grief reaction following the death of a loved one,${ }^{27}$ it is clear that some bereaved family caregivers do exhibit elevated levels of distress following the death of the person for whom they were caring. ${ }^{28,29}$ 
There are three distinct methodological limitations in existing caring and bereavement literature. First, family caregivers' perspectives on preparing for the death of the person for whom they are caring are typically assumed and not assessed. ${ }^{21}$ However, research shows that, despite engaging in high-intensity care of months and years, approximately a quarter of caregivers are not prepared for the death of their loved one; ${ }^{5,30}$ this means that researchers might assume that family caregivers are preparing for the impending death when they are not. Second, the effect of family caregiving on post-death adjustment tends to be assessed qualitatively, cross-sectionally and/or retrospectively ${ }^{29,31-33}$ or over a very short period of time, ${ }^{34,35}$ or with just two data collection points. ${ }^{32,34,35}$ Third, there are several longitudinal studies without adequate comparison groups ${ }^{28,36}$ whereby participants are compared to a noncaregiving sample matched to key demographics such as age, sex, domestic arrangements, and household income. These limitations exist across studies of caregivers of patients with a variety of chronic illnesses. Such limitations may exist due to the complexity in conducting research on family caregivers. Issues affecting research include the difficulties in recruiting and retaining participants and the challenges in gaining ethical approval. ${ }^{37}$ The studies on caring and post-bereavement distress have tended to overlook that, as a consequence of caring for a dying loved one, family caregivers may be highly distressed upon bereavement. Thus, even if a former caregiver's distress decreases over time, it cannot necessarily be concluded that this is a return to 'normal.'

\section{Implications for Palliative Care Research and Practice}

Clearly then, there is a need for research that addresses two important gaps in the literature on the effects of caregiving and bereavement: (1) family caregivers' understandings and experiences of the anticipating and preparing for the death of the person for whom they are caring, and (2) the relationship between family caregivers' pre-death grief and distress and post-death adjustment. In terms of the latter, a longitudinal, prospective approach is 
necessary to assess changes in the grief response over time and the use of comparison groups would allow the caregivers' distress in relation to non-caregivers (a normative group) to be assessed. Such research would be innovative and unique because it would overcome the three methodological flaws identified above and would therefore provide a significant contribution to our understanding of the effects of caring on bereavement.

In addition to these theoretical outcomes, the investigation of the effect of family caregiving on bereavement outcome will inform services and supports offered to caregivers, pre- and post-bereavement. Despite approximately 10 to $20 \%$ of bereaved individuals demonstrating persistent psychiatric difficulties, ${ }^{38,39}$ formal services and supports available to family caregivers pre- and post-bereavement in Australia, the United Kingdom, and the United States struggle with how to use their limited resources to deliver best-practice bereavement support. ${ }^{40-44}$ For instance, a survey of Australian palliative care services ${ }^{43}$ determined that, although 95\% (of 236 services) offered some form of bereavement support, the variability between services resulted from a "lack of clear evidence to guide development and allocation of bereavement programs in palliative care" (p. 230).

Furthermore, such research would complement the current call for evidence-based approaches to bereavement support in palliative care, as evidenced in the palliative care strategies of Australia, ${ }^{45}$ the United States, ${ }^{46}$ and the United Kingdom. ${ }^{47}$ Authors of a recent systematic review of interventions for family caregivers of palliative care concluded that without significant research investment, health professionals would continue to operate without a suitable evidence base to support them. ${ }^{48}$ Indeed, Australian palliative care services rate bereavement care as the area of highest priority for improvement. ${ }^{49}$ Thus, the results have the potential to inform palliative care policy and practice in the provision of supports and services for family caregivers following bereavement.

\section{Conclusion}


There is a clear need for research to address the critical theoretical and methodological gaps identified above. While health sectors faces huge financial strains in caring for people in their last year of life,${ }^{50,51}$ family caregivers absorb most of the cost. ${ }^{52}$ It is apparent that, if caregivers of people with chronic and life-limiting or terminal illnesses ceased caring, the cost to government, health services, and taxpayers would increase tremendously. Thus, there is a clear need for research to make a significant contribution to the theoretical conceptualisation of death and dying and enhance the capacity to provide appropriate supports and services to family caregivers pre- and post-bereavement, which will promote the wellbeing of the large number of caregivers in our communities and support their return to full participation in social and economic life, post-bereavement. An additional benefit of such research is that it may call attention to cost-effectiveness of supporting the needs of these family caregivers while they care and while they grieve. 


\section{Acknowledgements}

This paper was funded by the Australian Research Council (DE120101640). I would like to thank the anonymous reviewers for their feedback on an earlier version of the manuscript. 


\section{References}

1. World Health Organization. Global status report on noncommunicable diseases 2010, Geneva: Author 2011. Accessed November $21^{\text {st }} 2011$ from http://www.who.int/nmh/publications/ncd_report2010/en/index.html

2. World Health Organization. Noncommunicable Diseases Country Profiles 2011, Geneva: Author 2011. Accessed November $21^{\text {st }} 2011$ from http://www.who.int/nmh/publications/ncd_report2010/en/index.html

3. Aoun S, Connors S, Priddis L, Breen LJ, Colyer S. Motor Neurone Disease family carers' experiences of caring and bereavement: an exploratory qualitative study. Palliat Med 2011; doi 10.1177/0269216311416036.

4. Aoun SM, Kristjanson LJ, Currow DC, Hudson PL. Caregiving for the terminally ill: at what cost? Palliat Med 2005; 19: 551-555.

5. McNamara B, Rosenwax L. Which carers of family members at the end of life need more support from health services and why? Soc Sci Med 2010; 70: 1035-1041.

6. Guilfoyle A, Breen L, Fisher C, O’Connor M. Understanding the burden on palliative care home carers: a phenomenological account. International Journal of Interdisciplinary Social Sciences 2008; 3(8): 39-48.

7. Haines IE. Managing patients with advanced cancer: the benefits of early referral for palliative care. Med J Aust 2011; 194: 107-108.

8. Berg-Weger M, Rubio DM, Tebb SS. Strengths-based family practice with family caregivers of the chronically ill: qualitative insights. Families in Society 2001; 82: 263 272.

9. Boerner K, Schulz R, Horowitz A. Positive aspects of caregiving and adaptation to bereavement. Psychology and Aging 2004; 19: 668-675. 
10. Australian Bureau of Statistics. A profile of carers in Australia (Cat. No. 4448.0), Canberra, Australia: Author 2008. Accessed December 15, 2009 from http://www.abs.gov.au/AUSSTATS/abs@.nsf/DetailsPage/4448.02008?OpenDocument

11. Eiser C, Upton P. Costs of caring for a child with cancer: a questionnaire survey. Child: Care, Health and Development 2006; 33: 455-459.

12. Hayman JA, Langa KM, Kabeto MU et al. Estimating the cost of informal caregiving for elderly patients with cancer. J Clin Oncol 2001; 19: 3219-3225.

13. Ontario Human Rights Commission. The cost of caring: Report on the consultation on discrimination on the basis of family status, Ontario Human Rights Commission, 2006. Accessed January 302009 from: http://www.ohrc.on.ca/en/resources/discussion_consultation/famconsult/pdf

14. Bee PE, Barnes P, Luker KA. A systematic review of informal caregivers' needs in providing home-based end-of-life care to people with cancer. J Clin Nurs 2009; 18: 1379-1393.

15. Wong, M-S, Chan, SW-C. The experiences of Chinese family members of terminally ill patients - a qualitative study. J Clin Nurs 2007; 16: 2357-2364.

16. National Audit Office. End of life care: Report by the Comptroller and Auditor General, London: The Stationery Office 2008. Accessed February 2, 2009, from http://www.nao.org.uk/publications/0708/end_of_life_care.aspx

17. McLaughlin D, Sullivan K, Hasson F. (2007). Hospice at Home service: the carer's perspective. Supportive Care in Cancer 2007; 15: 163-170.

18. Vanderwerker LC, Laff RE, Kadan-Lottick NS, McColl S, Prigerson HG. Psychiatric disorders and mental health service use among caregivers of advanced cancer patients. $\mathrm{J}$ Clin Oncol 2005; 23: 6899-6907. 
19. Galfin JM, Watkins ER. Construal level, rumination, and psychological distress in palliative care. Psychooncology. 2011; doi: 10.1002/pon.1948.

20. Harding R, List S, Epiphaniou E, Jones H. How can informal caregivers in cancer and palliative care be supported? An updated systematic literature review of interventions and their effectiveness. Palliat Med 2011; 26: 7-22.

21. Schulz R, Boerner K, Hebert RS. Caregiving and bereavement. In: Stroebe MS, Hansson RO, Schut H, Stroebe W eds: Handbook of bereavement research and practice: Advances in theory and intervention, Washington, DC: American Psychological Association 2008: 265-285.

22. Lindemann E. Symptomatology and management of acute grief. Am J Psychiatry 1944; 101: 141-148.

23. Parkes CM, Weiss RS. Recovery from bereavement. New York: Basic Books, 1983.

24. Breen LJ, O’Connor M. The fundamental paradox in the grief literature: a critical reflection. Omega: The Journal of Death and Dying 2007; 55: 199-218.

25. Saldinger A, Cain AC. Deromanticizing anticipated death: denial, disbelief, and disconnection in bereaved spouses. J Psychosocial Oncol 2004; 23(3): 69-92.

26. Schulz R, Newsom JT, Fleissner K, deCamp AR, Nieboer AP. The effects of bereavement after family caregiving. Aging and Mental Health 1997; 1: 269-282.

27. Bonanno GA, Boerner K, Wortman CB. Trajectories of grieving. In: Stroebe MS, Hansson RO, Schut H, Stroebe W eds: Handbook of bereavement research and practice: Advances in theory and intervention, Washington, DC: American Psychological Association 2008: 287-307.

28. Aneshensel CS, Botticello AL, Yamamoto-Mitani N. When caregiving ends: the course of depressive symptoms after bereavement. J Health Soc Behavior 2004; 45: 422-440. 
29. Bonnano GA, Moskowitz JT, Papa A, Folkman, S. Resilience to loss in bereaved spouses, bereaved parents, and bereaved gay men. J Personality Soc Psychol 2005; 88: 827-843.

30. Hebert R, Dang Q, Schulz R. Preparedness for the death of a loved one and mental health in bereaved caregivers of patients with dementia: findings from the REACH study. $\mathrm{J}$ Palliat Med 2006; 9: 683-693.

31. Dumont I, Dumont S, Mongeau S. End-of-life care and the grieving process: family caregivers who have experienced the loss of a terminal-phase cancer patient. Qualitative Health Research 2008; 18: 1049-1061.

32. Grande GE, Farquhar MC, Barclay SIG, Todd CJ. Caregiver bereavement outcome: relationship with hospice at home, satisfaction with care, and home death. J Palliat Care 2004; 20(2): 69-77.

33. Koop PM, Strang VR. The bereavement experience following home-based family caregiving for persons with advanced cancer. Clin Nurs Research 2003;12:127-144.

34. Gilliland G, Fleming S. A comparison of spousal anticipatory grief and conventional grief. Death Stud 1998; 22: 541-569.

35. Kelly B, Edwards P, Synott R, Neil C, Baillie R, Battistutta D. Predictors of bereavement outcome for family carers of cancer patients. Psycho-oncology 1999; 8: 237-249.

36. Ferrario SR, Cardillo V, Vacario F, Balzarini E, Zotti AM. Advanced cancer at home: caregiving and bereavement. Palliat Med 2004; 18: 129-136.

37. O’Mara AM, St. Germain D, Ferrell B, Bornemann T. (2009) Challenges to and lessons learned from conducting palliative care research. J Pain Symptom Manage 2009; 37 : 387-394.

38. Lobb EA, Kristjanson L, Aoun S, Monterosso L, Halkett GKB, Davies A. Predictors of complicated grief: a systematic review of empirical studies. Death Stud 2010; 34: 1-26. 
39. Prigerson HG, Vanderwerker LC, Maciejewski PK. A case for inclusion of prolonged grief disorder in DSM-IV. In: Stroebe MS, Hansson RO, Schut H, Stroebe W eds: Handbook of bereavement research and practice: Advances in theory and intervention. Washington, DC: American Psychological Association, 2008, pp. 165-186.

40. Abbott J, O'Connor M, Payne, S. An Australian survey of palliative care and hospice bereavement services. Aust J Cancer Nurs 2008; 9(2): 12-17.

41. Aoun S, Breen LJ, O’Connor M, Nordstrom C, Rumbold B. A public health approach to bereavement support services in palliative care. Aust N Z J Public Health in press.

42. deCinque N, Monterosso L, Dadd G, Sidhu R, Macpherson R, Aoun S. Bereavement support for families following the death of a child from cancer: experience of bereaved parents. J Psychosocial Oncol 2006; 24(2): 65-83.

43. Mather MA, Good PD, Cavenagh JD, Ravenscroft PJ. Survey of bereavement support provided by Australian palliative care services. Med J Aust 2008; 188: 228-230.

44. O'Connor M, Abbott J, Payne S, Demmer C. A comparison of bereavement services provided in hospice and palliative care settings in Australia, the UK and the USA. Progress in Palliative Care 2009; 17(2): 69-74.

45. National palliative care strategy. Commonwealth of Australia. Author, Barton, Australian Capital Territory, Australia, 2010. Accessed 21 ${ }^{\text {st }}$ September 2011 from http://www.health.gov.au/internet/main/publishing.nsf/Content/palliativecarestrategy.htm

46. National Hospice and Palliative Care Organization. Guidelines for bereavement care in hospice $2^{\text {nd }}$ edn. Alexandria, VA: Author 2008.

47. National Institute for Health and Clinical Excellence. Guidance on cancer services: Improving supportive and palliative care for adults with cancer. The Manual, London: 
Author 2004. Accessed 25 ${ }^{\text {th }}$ January 2011 from:

http://guidance.nice.org.uk/CSGSP/Guidance/pdf/English

48. Hudson PL, Remedios C, Thomas K. A systematic review of psychosocial interventions for family carers and palliative care patients. BMC Palliat Care 2010; 9: 17.

49. Palliative Care Australia. National Standards Assessment Program: National quality report, Deakin West, Australian Capital Territory, Australia: Author 2010. Accessed $21^{\text {st }}$ September 2011 from

http://www.standards.palliativecare.org.au/Portals/20/NSAP\%20National\%20Quality\%2 0Report.pdf

50. de Kok IMCM, Polder JJ, Habbema JDF et al. The impact of healthcare costs in the last year of life and in all life years gained on the cost-effectiveness of cancer screening. $\mathrm{Br} \mathbf{J}$ Cancer 2009; 100: 1240-1244.

51. Kardamandias K, Lim K, Da Cunha C, Taylor LK, Jorm LR. Hospital costs of older people in New South Wales in the last year of life. Med J Aust 2007; 87: 383-386.

52. Grande G, Stajduhar K, Aoun S et al. Supporting lay carers in end of life care: current gaps and future priorities. Palliat Med 2009; 23: 339-344. 